\title{
Match-fixing as a Threat to Sport: Ethical and Legal Perspectives
}

\author{
Ladislav Mravec \\ Department of Kinanthropology and Humanities, Faculty of Physical Education and Sport, Charles University, \\ Prague, Czech Republic \\ Correspondence: Ladislav Mravec, UK FTVS, José Martího 31, 162 52, Praha 6-Veleslavín; Czech Republic, \\ email: ladislavmravec@gmail.com
}

\begin{abstract}
This article aims to show how match-fixing is a threat to sport, not only from an ethical but also from a legal perspective, and to explain the various challenges of combating match-fixing in sport on the national and international level. To achieve this, the first step of the article is to explain corruption in sport, the values of sport and their endangerment through match-fixing, and then the crucial factor of sport autonomy is explained. Further, the article discusses various national and international legal norms and measures in the fight against match-fixing. On the international level there is discussed the current state of play of the Council of Europe Convention on the Manipulation of Sports Competitions (the so-called Macolin Convention) and the Group of Copenhagen, as the follow-up network of national platforms. Finally, the article makes recommendations regarding the better investigation of match-fixing and concludes with a critical appreciation of findings in the fight against match-fixing.
\end{abstract}

Key words: legislation in sport, negative aspect, match-fixing, corruption, integrity

\section{INTRODUCTION}

In the world of sports, there have been many betting scandals spanning over the last two decades. Stakeholders have come to realize that values in sports have changed due to the commercialization and globalization of sport. In the White Paper on Sport, the European Commission mentioned that sport is confronted with new threats and challenges such as commercial pressure, corruption, and money laundering. (European Commission, 2007, 2). Thus, the spread of commercialization in sport has brought a fundamental change in values, and economic interest in sport is now becoming more critical. In particular, the internal ethical values of sport, such as fair play, respect, and self-discipline have now taken a shift towards the external values of the pursuit of power and money. (Trunz, 2016, 10). The economic potential of sport within the sports betting market brought the risk that matches could be influenced by illegal machinations. Numerous senior sports administrators have openly cited match-fixing as the biggest threat to sport, even as far as describing match-fixing as a more significant threat to the integrity of sport than doping. (EUROPOL, 2020, 5)

Sports participants recognize that no-one is immune to this phenomenon, and that anyone may become a victim either directly or indirectly, be they athletes, coaches, referees, administrators, betting companies and their customers, or spectators. Any sport is considered endangered where it is possible to bet; and thus, the whole sports industry is at risk of reputational damage, since intrinsic value has been compromised, affecting the credibility of the sport.

There exists match-fixing with the element of betting as well as match-fixing without the betting element (i.e. with only sporting implications). Match-fixing with the betting element is much more prevalent and significant due to the influence of criminal organizations of all levels. It is estimated that around \$US140 billion is laundered every year through sports bets, which 
means that organized crime launders more than $10 \%$ of its worldwide revenue through sports bets. (ICSS, 2014, 29) This percentage reflects only those manipulated matches of which we are aware, so that the real figures are unknown.

The state can regulate the sports betting market and can prosecute criminal activity only on its territory, whereas match-fixing with the element of betting occurs on an international level. To effectively fight against match-fixing, there is a need for international cooperation and a globally viable approach for combating game and match manipulation in sport.

\section{Corruption in Sport}

Corruption in sport is not fundamentally different from corruption in other sectors, except that it happens in sports circles. In sports corruption, individuals or groups are influenced by various factors that make them willing to abandon ethical and moral principles. When identifying them, it is necessary to focus on the modus operandi of individual corruptors, which, in a negative sense, means the characteristics of the implementation of corruption or the actors' means and methods.

Persons involved in individual cases of corruption usually stick together and agree a nonaggression pact, or omerta. Omerta is criminal solidarity and has its origins in an unwritten mafia code, which emphasizes the duty of confidentiality against the police, the authorities and foreigners; non-cooperation with authorities, government, or strangers; and the obligation to intentionally ignore and generally avoid interfering in the illegal activities of others, i.e., not to 'grass' (to inform law enforcement or the authorities when an individual is aware of a crime, witnesses it or is even its victim). Corruption involves ways of working that are typical of organized criminal organizations, in which people with corrupt practices organize themselves to create synergies that give them more power, influence, and money that they would never have accumulated if they acted individually and borrowed money legally and through legitimate channels. Corruption networks use the same structures, methods, and techniques as the mafia network. The problem arises for them when members of the association break this unwritten promise. EUROPOL reports that these criminal networks include investors, facilitators, and runners. At the so-called lower level are corrupted athletes, referees, club officials, player agents, etc. These actors coordinate their activities to manipulate those sports events to obtain a financial gain through betting. (EUROPOL, 2020, 5)

\section{Values of Sport and their Endangerment through Match-fixing}

In referring to the values of sport, I will treat legal and moral principles more or less interchangeably, since for my purposes in this essay the differences are unimportant. On the nature of the relation between moral and legal principles I rely on Honoré (2002), who argues that critical morality is the source of law.

According to the European Sports Charter of the Council of Europe, "Sport means all forms of physical activity which, through casual or organized participation, aim at expressing or improving physical fitness and mental well-being, forming social relationships or obtaining results in competition at all levels. (Council of Europe, 1992, Art. 2. paragraph i. a)

Sport has some basic principles that derive from the practice of sport itself. Parry outlines and justifies a 6-criteria conceptual analysis, which defines sport. Sport is 'human', 'physical', involves 'skill', 'contest', is 'rule-governed' and 'institutionalized'. If we take just two of them, 'rule-governed' and 'contest', it is obvious that these criteria require adherence to certain internal values of sport, such as equality, fairness, and justice. Without agreement on rule-adherence and the central shared values of the activity, there is no contest and there could be no sport. (Parry, 2020, 140).

From this we can see that the most important principle of sport is the principle of competition. If you do not have an opponent, you cannot compete. The second basic principle of sport is the 
principle of fairness or fair play. The meaning of this principle lies in the agreement to compete against the opponent following the rules and fairly during the whole competition. It means that everybody should compete in fair circumstances, start from the same starting line, have the same equipment, and operate under the same rules. This follows another basic principle - the principle of equal opportunities, which presupposes that every sporting competition should take place under the same conditions which are valid for everybody.

When thinking about match-fixing, an important consideration is the feature of sport which has been described the "sweet tension of uncertainty of outcome" of a sporting contest. (Kretchmar, 1974, 26). At the beginning of every sporting competition the outcome of the competition is more or less uncertain, and this is one of the reasons why we are interested in sports, why sport is attractive to us and why sport has such a positive image. (European Commission, 2007, 3). Match-fixing puts this most important feature of sport into question, since it seeks to make outcomes less certain, or even (if it can possibly succeed in doing so) to eliminate uncertainty of outcome.

Trunz divides the threats to the external values of sport by match-fixing into six spheres. First are the increasing internationalization and commercialization of sport; second, the offshore states and non-transparent sports betting market; third, the large unregulated betting market in Asia; fourth, organized crime in the sports betting market; fifth, the addictive potential of bettors; and sixth, the particular danger in amateur and junior games. (Trunz, 2016, 8-18).

Internationalization in sport means that modern sport is no longer national but rather international. International sports organizations are created and influenced by their regional, national and continental sports associations, together with whom they must work and cooperate. Along with internationalization, sport has also been affected by massive commercialization, which has influenced the transition from amateurism to professionalism. Professional clubs gain income from club fees, ticket sales, sponsorship money, and equipment contracts, and also from intellectual property rights such as copyrights, trademarks, and media rights.

The sports betting market has also been developed for an international business community, with more than 8000 sports betting operators in the world. Importantly, around $80 \%$ of these operators are established in low tax rate territories or tax havens such as Gibraltar, Isle of Man, Malta, etc. (ICSS, 2014, 12) The internationalization of sports and the sports betting market makes it clear that match-fixing is not a national but an international problem.

Currently, football is the most targeted and manipulated sport by international organized criminal groups (OCGs) due to its worldwide popularity, financial dimension, and large turnover betting market. The money generated globally on football betting is reported to be annual $€ 895$ billion, and the estimated annual gross amount of bets in sports amount to $€ 1.69$ trillion. (EUROPOL, 2020, 15) Despite the fact that football remains the most targeted sport by international OCGs, tennis is also implicated, with an increase in the detection of match-fixing schemes in tennis (Hutchins, 2014, 52), in which Eurasian OCGs are highly involved. (EUROPOL, 2020, 2)

The second threat to sports values is the offshore states and the non-transparent sports betting market. The taxes collected from the sports betting business are in many countries used to finance sports associations and clubs. On the other hand, if bettors use online-based betting providers or the ones operating from offshore states - such as Malta, Gibraltar, or the Isle of Man, sport is losing these taxes and must search for replacement of these incomes. The income from the gaming industry creates a significant share of GDP. In Malta itself, at the end of December 2019, there were 294 companies licensed by the Malta Gaming Authority, including both online and land-based entities, which together generated $€ 1.6$ billion in terms of GVA in 2019, increasing the gaming industry's share in economic activity to $13.3 \%$. (Yogonet Gaming News, 2020) 
The third threat to sports values is the large unregulated betting market in Asia. The main difference between betting markets between Europe and Asia lies in the regulations. The markets are more regulated in Europe than Asia, where the betting markets are mostly unregulated and untransparent black markets.

The fourth threat to sports values is that organized crime in the sports betting market is highly active. Criminal organizations are interested in the sports betting market because of its great economic potential and the low risk of detection. Criminal organizations operating in the betting market have hundreds of agents or so-called 'runners' around the world, and this number of people involved makes it difficult to uncover cases. Betting activities in context of matchfixing allows criminal organizations to launder their money in the black market. It is estimated that organized crime launders more than $10 \%$ of its worldwide revenue through sports bets. (ICSS, 2014, 29) Organized criminals are engaged in match-fixing because of the low risk and high-reward activity with a view of potentially huge profits from betting markets. The working methods of these groups are mostly bribery, coercion, and blackmail. (Boeri \& Battista, 2013, 107) The standard of proof in criminal cases is 'beyond a reasonable doubt', and the evidence from the investigation of match-fixing cases is mostly insufficient to reach this level of standard. For example, consider the case of two Brazilian football referees, Edilson Pereira de Carvalho and Paulo Jose Danelon, who faced criminal charges as being part of the match-fixing mafia, but later their criminal action was suspended due to insufficient evidence. (Godinho \& Barbosa, 2013, 229)

The fifth threat to the values of sport is the possible addictive potential of bettors. The runners who usually try to fix a match look for vulnerable players. They might have financial or family problems, or they might be addicted to gaming, drugs, or prostitution. (EUROPOL, 2020, 11) If these addicted bettors are players or referees, it is easier to bribe them.

The sixth threat to the values of sport is the danger in amateur and junior games. A large fraction of match-fixing cases occurs in the amateur and junior sectors, which mostly cannot be detected due to a lack of resources. This lack of resources for the detection of fraud, and lack of surveillance systems of competitions in lower leagues, women's team sports competitions, and junior competitions also leads to the conclusion that the identified cases make up only the 'tip of the iceberg', and the real number of uncovered manipulated cases could be much bigger. (ICSS, 2014, 4)

\section{Sport Autonomy as a Crucial Factor}

At their $5^{\text {th }}$ International Conference of Ministers and Senior Officials Responsible for Physical Education and Sport, held in Berlin 28-30 May 2013, the United Nations created a Declaration of Berlin, where there they stated that "the autonomy of sports organizations is closely linked to their primary responsibility for the integrity of sport and the compliance with the general principles and international standards of good governance." An organization cannot have autonomy, if it doesn't bear responsibility for its actions and doesn't follow international standards regarding good governance in sport.

The high degree of autonomy of sport is one of the fundamental problems of corruption in sport, since it creates space to circumvent society's rules. However, the responsibility for assessing corruption offences in sport is the responsibility of individual countries; corruption should, therefore, be assessed only based on national laws. The European Parliament also points out in its resolution of 11 June 2013 on organized crime, corruption, and money laundering that selfregulation as a natural mechanism for tackling corruption in sport and betting on sports competitions has proved ineffective. Sports federations alone are not able to deal with these cases of corruption in their competence, and many cases need to be dealt with by national law enforcement authorities. (Machová, 2015) 
The autonomy of associations is limited by the rules and regulations of the society within which it operates. If associations, which usually take the legal form of civil associations, are not capable of taking responsibility for their actions or non-actions, the role of the state is to enforce the rule of law. Sport and sports associations went through the transformation from amateurism to professionalism. Most sports associations nowadays are in the mode of business companies with receipts and expenditures, but some of them are organisationally stuck in amateurism. This may be due to the fact that many people in the world of sport are working as volunteers but, on the other hand, these institutions should work professionally and are responsible to their members and also taxpayers, because sports associations are often partially subsidized by taxpayers.

\section{Match-fixing}

According to the United Nations, the key offence which occurs in match-fixing is bribery with money or another pecuniary benefit paid by the criminal person. The transfer of funds happens mostly through a third party to the direct actor in a match, such as a player or a referee, to manipulate the result of a particular sporting competition. (United Nations, 2016, 77)

It is not surprising that OCGs use sport to launder money acquired from illegal activities. The whole process of money laundering is completed after fixing a match - placing a bet and receiving money back through legitimate channels. This happens through betting operators, but it can also be achieved through buying or investing in clubs and players. (United Nations, 2016, 77)

Sport and sports betting have great economic potential. There is evidence that hundreds of sports competitions are manipulated by players and referees worldwide. (ICSS, 2014, 6) This form of match-fixing is a profit-maximizing form, which requires contacts and financial arrangements between gamblers, criminals, players, team officials and referees, umpires, judges, or other officials.

Players or referees are usually approached by criminal gangs, who are willing to pay them tens of thousands of dollars to control the game according to their instructions while making hundreds of thousands or even millions of dollars by betting on an almost certain result. The money spent on bribing individuals represents a negligible investment for betting gangs, which is within $10 \%$ of the potential return. (Perumal, 2014) In the current boom of online betting, where huge amounts of money are being wagered for popular sports matches, especially in Asia, the impact on the outcome of a competition or part of it is potentially huge and fundamentally untraceable. Especially in mega-events such as the World Cup and the Olympics, there are no regular betting patterns because it is mostly regular people, who do not bet regularly, who bet on these matches. This type of corruption can be detected mostly in cases where an unexpectedly large amount of money is placed on a relatively uninteresting match in a lower league - for example, when the usual amount of funds in a second-league football match increases several times. (Hill, 2008, 28) Match-fixing linked with betting activities is therefore a fundamental threat to sports as such.

Since the sports betting market has tremendous financial potential, it is no surprise that it attracts the interest of organized crime. Match manipulation and sports betting is a new way of investment, which is very hard to prosecute because most fixed matches and betting frauds occur on the international level. Match-fixing grew when the betting market went online and became international, while individual states had no jurisdiction beyond their own borders, and had to rely on international cooperation. In addition, the international betting market was very much unregulated, providing considerable opportunities to bet online in anonymous spaces. This provides attractive potential for money laundering, since bets can be placed in cash and without any check on where the money comes from, and this reduces risk. A criminal organization can invest some ten thousand euros in bribing a referee but can make betting gains of hundreds of thousands. 
The issue of transnationality requires elaboration. A bettor can place an internet bet on a sports competition in another country, through betting operators from yet another country, whose online betting platform is accessible from almost anywhere globally, whilst based in a country where the betting market is unregulated. In addition, corrupt match-fixing activities occur through intermediaries in different countries, who place a bet on a lower league match. Law enforcement in that country is then confronted with corrupt activity occurring locally, whilst organized from elsewhere, with bets being placed in a third country.

There is also problem with transnational legal standards. A particular behaviour might be prohibited in one country, but not in the country where the betting platform operates. Furthermore, sports federations do not have the same investigatory power as do states, and so they must rely on cooperation and support with government and state authorities. If the state authorities are not interested in match-fixing or not capable of solving the problems of sports manipulation in certain countries, then sports federations have a fundamental problem.

One of the most famous match-fixers, Wilson Raj Perumal, said: "Money is the root of corruption and everyone's concern. Everyone needs money to take the next step in life, and those who do not have it are the most vulnerable. If you face players who have never had a lot of money and offer them a good amount for their troubles, they will rarely reject them." (Perumal, 2014) Active police investigations of affected matches are underway in more than sixty countries, approximately one-third of the world. (Forrest, 2014)

\section{The Legal Basis on the National State Level}

Match-fixing or corruption in sport is regulated in various countries according to various codes. Some of them regulate match-fixing with general provisions in Criminal Codes, others through Gambling Acts, when match-fixing involves an element of betting. Many countries have made match-fixing a separate criminal offence in recent years rather than rely on existing general provisions incriminating fraud, bribery, cheating, corruption, or deception. (IOC, 2016, 70)

Finland and Austria have regulated cases of match-fixing under the general crime of fraud. Norway is using general criminal law provisions on fraud and corruption. Sweden is also using general provisions on active and passive corruption. Luxembourg, in cases of sports bribery, uses general provisions on corruption. (Gábriš, 2017, 17)

Separate offences have been created either within the general criminal codes, e.g., in Australia, Bulgaria, France, New Zealand, Spain, or Ukraine. (IOC, 2016, 70-71) Separate offences have been created either within the country's law on sports or gambling, e.g., in Argentina, Brazil, China, Italy, Greece, Korea, Malta, Poland, Portugal, Russia, Switzerland the UK. Northern Ireland is one of those countries which regulate match-fixing under the Gambling Act; specifically, they consider match-fixing as fraud under the law on gambling. In the case of Switzerland, the legal basis on the national level influences not only Switzerland, but is also extended on the international level. Switzerland, which is the seat of more than half the Olympic sports federations, including the IOC, FIFA, and UEFA, is directly impacted if there is corruption in sport. (Bradley, 2014).

It is very difficult to prove the manipulation of sports competition, and so criminal offences and sanctions should seek to deter. Secondly, a special type of offence helps, where the perpetrators can are aware that the crime they are committing is seriously punishable. It is also highly recommended to distinguish between a betting-related offence and a merely sports-related offence.

In many countries there have been changes in legislation to implement a special type of offence such as sports fraud or the crime of match-fixing and stricter penalization of corruption in sport - for example, in Denmark, Montenegro, Malta, Lithuania, Hungary, Ukraine, Turkey, Estonia, Azerbaijan, Latvia, and Italy. (Gábriš, 2017, 17-18) 


\section{The Legal Basis on the International State Level}

Globalization and technical revolution in the last 20 years has exponentially transformed the world we used to know. The same is valid in sport, in which organized crime operates globally. The only effective answer to these global problems is with global solutions. These solutions require intensive cooperation between the states in terms of common approaches and principles. It is not easy due to different approaches in the regulation of betting markets and criminal prosecution of match-fixing. Due to the international nature of match-fixing, single states are not able to prevent and detect these cases, and so this problem must be dealt with and solved at the international level.

There are some international organizations that have started to be active in the field of matchfixing and sports manipulation on the international level. The most important players are the Council of Europe, the United Nations and the European Union. The most important adopted document is the International Convention on the Manipulation of Sports Competitions, which was open to signatures in September 2014 in Macolin, Switzerland.

\section{The current state of play of the Macolin Convention}

The Macolin Convention is open for signature not only for the member states of the Council of Europe but also for other Parties such as members of the European Cultural Convention, the European Union, non-member States or states having observer status with the Council of Europe. In the meantime, 38 states have signed the Convention, among them Australia as the only one non-Member of the Council of Europe. The Convention on the Manipulation of Sports Competitions was ratified by the parliaments of 7 signatory states, namely by the date of ratifying by Norway, Portugal, Ukraine, Republic of Moldova, Switzerland, Italy, and Greece, and entered into force on 1st September 2019. (Council of Europe, 2021)

The Macolin Convention was the first international agreement dealing with the problem of match-fixing on such a scale. It is until now, along with the Group of Copenhagen, the best solution for state authorities, betting authorities, and sports organizations to meet, discuss and adopt effective measures against match-fixing. The advantage of the Convention is the recognition of stakeholders across various sectors, the so-called multi-stakeholder approach, which can adopt global measures to tackle match-fixing. It is at the same time a burden to find a consensus on common measures because different states and even organizations within one state have different interests. States have different state approaches in the field of regulation of the sports betting market and in the criminal prosecution of match-fixing. The Convention does not seek to standardize national legal norms; in any case, this is not possible with so many stakeholders, approaches, regulations, etc. The goal of the Convention is to call on states to review their legal state norms and, in the light of the fight against match-fixing, if it is needed, to adopt new measures. However, some degree of harmonization would be necessary to effectively combat match-fixing. Most likely, it would go in the same direction as the adoption of other conventions that are under the Council of Europe in other areas such as anti-doping or spectator violence and misbehavior at sports events. The follow-up committee will be replaced by a Standing committee, and it would adopt and revise recommendations to implement the Convention.

The actual definition of match-fixing adopted in the Convention is open to criticism, since it fails to make the distinction between match-fixing with and without the element of betting, and the difference in risk of these two types of match-fixing is obvious. To begin with, there is a lack of proportionality. We should not compare an offence of match-fixing of global impact (i.e., a fixed match at the World Cup, where criminal organizations are bribing direct actors in the match and are placing bets around the world along with money-laundering) with a match-fixing case of a club needing to win to avoid relegation to a lower division. There is also a difference in 
terms of the of actors involved. Given a case of match-fixing without the betting element (i.e. for sporting purposes only) it is difficult to prove that anything else was corrupted other than the integrity of the match and the spirit of sport. So the impact of these two very different types of match-fixing has something in common, but many other issues are divergent.

Some states of the Council of Europe, particularly Malta, criticized the definition of illegal sports betting, causing an 'institutional deadlock' referred to the Convention. The definition is as follows: "illegal sports betting means any sports betting activity whose type or operator is not allowed under the applicable law of the jurisdiction where the consumer is located." But if we take the example of Malta, it is not clear which jurisdiction should be preferred. The primacy of EU law is not explicitly laid down in a TFEU but refers to the case-law of the Court of Justice (CJEU) that is relevant to the question of primacy. The primacy of Union law ensures that Union law may not be revoked or amended by national law, and it takes precedence over national law if the two conflict. Malta states that the definition of illegal sports betting is beyond the scope of the Macolin Convention and, therefore, does not contribute to the fight against match-fixing. We do not know whether Malta was involved in drafting the latest version of the Convention or could comment on it, but neither Malta nor any other country whose domestic market is dependent on the profits of the gaming industry will sign the document in such a version. If betting operators with a base in Malta offer their services for customers from other EU member states, it is absolutely in line with Union law, and therefore, the aforementioned definition of illegal sports betting is incorrectly worded and against the interests of Malta or other states strongly dependent on the gaming industry.

In a relatively new report from the Committee on Culture, Science, Education, and Media, a rapporteur from Switzerland states that Malta imposed on the Convention a years-long deadlock over the definition of illegal sports betting. (Büchel, 2020). Malta argues that "betting services should benefit from free movement under the Internal Market rules whereby a service licensed in one Member State should be accepted in all others. However, it is perfectly clear from the jurisprudence of the CJEU that the principle of mutual recognition is not applicable in this area." (ibid.)

Legislators drafting the Macolin Convention can always revise the document in the future or prove that Malta's position is wrong as well as prove that Malta is involved in activities of the illegal betting market, but not according to the definition stated in the Convention, but according to International Law. The definition of the legality of sports betting in Europe, as it is stated in the Convention, and the regulated betting market in Europe, is not the real problem in the fight against match-fixing. It is a fact that most cases of match-fixing take place on the unregulated or black market, mostly in Asia, whose countries would probably not be interested in signing and ratifying the Macolin Convention in any case.

The Convention aims to ensure that the provisions can be applied to all regulatory models of the sports betting market. But illegal sports betting operators would not like to cooperate with the state authorities and with the sports associations. They would like to operate without any control and thus represent a threat in the area of match-fixing. (Council of Europe, 2014, 18, Rn. 110.) However, to prevent match-fixing, it would be helpful to define a minimum standard that would apply to all sports betting operators.

Nevertheless, it is the first document of an international character of the Council of Europe, which has a very ambitious goal, suggesting that the Council of Europe wants to become the international body that will address the problem and attract non-member states in the fight against match-fixing. So far, only Australia, which also cooperated in drafting the Convention, is such a signing party. It is a question for the future whether countries in Asia, where the most unregulated betting companies operate, will also sign the Convention and join the countries that consider match-fixing a threat. 


\section{The Group of Copenhagen}

Two years after the Macolin Convention was opened for signature by the member states, the Council of Europe established a Group of Copenhagen, which is the Council of Europe's Network of National Platforms. Its role is to promote transnational cooperation in the fight against matchfixing and the exchange of information on national platforms. (Council of Europe, 2020).

The priorities of the Group of Copenhagen are to support other $\mathrm{CoE}$ member states to create their national platform, to provide support to existing national platforms, and to identify and share best practices of these national platforms. The Group of Copenhagen has set up its own Alert and Surveillance System to strengthen National Platforms' responsiveness to all forms of manipulation, which identifies different types of manipulation and alerts the responsible actors. (ibid.) Some of the National Platforms are currently only formal and do not work as yet. However, it gives the opportunity for relatively undeveloped national platforms to take a lesson from other well-functioning platforms.

The Council of Europe has started an informal cooperation framework with the Group of Copenhagen, even though legal actions against organized crime cannot be laid down on the basis of informal cooperation. First of all, there has to be a formal legal framework. It is crucial to have effective cooperation in the exchange of information among this group and CoE for effective criminal inquiries and pursuits. Otherwise, there could not be an effective investigation and prosecution of suspected natural and legal persons. (Buchel, 2020).

It is necessary to create national platforms for the fight against match-fixing at the national and international levels. These platforms can present with various forms and structures that can be either formal or informal governmental or non-governmental organizations or even a hotline.

Match-fixing is mostly a form of corruption in the private sector, where private entities are involved. So it is essential for law enforcement authorities to cooperate with sport governing bodies, betting regulators, and betting operators. (United Nations, 2016, 80, Art. 39) The establishment of national platforms that are responsible for the fight against match-fixing should also be the backbone of the global approach. These member networks would fill the database with information on best practices and alerts of potential threats of match-fixing.

\section{Better investigation of match-fixing}

One of the main means of effectively fighting against match-fixing is to better investigate all participants involved in fixing a match in order to deter them and others from this kind of breach of the integrity of the sport. The accused person should be investigated and, in the case of any proof, prosecuted. There are many participants called runners who act as agents and third parties between the criminals fixing a match and the actors on the pitch. Not only successfully fixed matches should be investigated and prosecuted, but also any attempts to do so. (United Nations, 2016, 78, Art. 27)

Law enforcement bodies in terms of anti-corruption law, depending on the strength of the evidence of an offence through match-fixing, should initiate an investigation and, depending on the strength of the evidence, prosecute all co-conspirators. (United Nations, 2016, 78, Art. 30) Investigation of these crimes and the actors of match-fixing, direct or indirect, could have a deterrent effect. In the investigation, it is suggested to apply the rule 'follow the money' as with any other form of corruption involving serious organized crime. Cooperation in these proceedings requires that betting operators and financial institutions work together. (United Nations, 2016, 78, Art. 31)

It is crucial to provide witnesses with the utmost protection when they decide to cooperate and testify against those convicted of the offence of match-fixing, especially if organized crime is involved, whose regular practice is to intimidate witnesses. If needed, the court can decide to 
accept the testimony of an anonymous witness for the purpose of identity protection. Testimonies of such witnesses are sometimes the only evidence which a prosecutor has in such a case. (United Nations, 2016, 79, Art. 32) Many states have an institute of active repentance, which allows for those involved in match-fixing offences to reduce their sentence if they fully cooperate with law enforcement entities, to which they would provide information or offer testimony in order to help the authorities to investigate higher up the chain of the organized crime group. (United Nations, 2016, 80, Art. 37)

Match-fixing offences where organized crime is involved have a cross-border element. If the offence occurred in two or more states, there should be a question of jurisdictional primacy. (United Nations, 2016, 81, Art. 42) To tackle a global phenomenon such as match-fixing and conduct an investigation, collect evidence and witnesses, international cooperation amongst offended states is of the utmost importance. If necessary, the state should cooperate and extradite the accused criminal to the jurisdiction which is leading the investigation. Mutual legal assistance is therefore important in the process of investigation and gathering evidence, which could be used in a trial. (United Nations, 2016, 84, Art. 46) Joint investigations by two or more states are also appropriate means in taking into account the complexity and transnationality of the investigation of a match-fixing offence. Corruption in sport is not new; however, developments in corruption involving the element of online betting, including transnational organized crime laundering money, is an intersectoral and global problem and thus must be solved with the same methods. As criminals are using the newest techniques, law enforcement authorities in particular states must also apply modern ICTs, if possible. (United Nations, 2016, 84, Art. 48)

\section{Conclusion}

Match-fixing is a complex phenomenon. The internationality of this phenomenon shows that it is impossible to tackle it on the national level. The best way to fight against match-fixing is on the global level, where intensive international cooperation is needed. To fight against match-fixing, all stakeholders should adopt a common approach. These include the betting providers, the state authorities, and sports associations with their clubs, athletes, coaches, referees, and officials.

State authorities and sports associations should coordinate their actions together - sports associations through their internal rules and regulations and state through its state law, particularly criminal law. Because rules and regulations of associations are valid for its members, but criminal law for all, it is possible to be sanctioned for the same offence twice. The ne bis in idem principle cannot be applied, since the sanction of an association can be understood as merely an administrative measure of an association to its members, whilst the sanction according to the valid penal code from a state is applied in the case of a violation of the law. Another advantage of cooperation between associations and states lies in the evidence. Associations cannot undertake real investigations, interceptions, question witnesses, etc. States can do this. After or even during state criminal proceedings, associations can get this evidence to start or continue their disciplinary proceedings.

Some countries where the fight against match-fixing is not a priority might ask: why not build a national platform and contribute to the global platform? One solution might be to join this anti-match-fixing platform under the national anti-doping agencies' activities, which deal with integrity in sport but from the medical point of view. The shining example is the national anti-match-fixing platform of Denmark, whose secretariat is operated by the Danish NADO. It is sometimes the easiest and fastest way of establishing a national platform. National anti-doping agencies already have a functioning organization, and they are active in the fields of education, awareness, testing, etc. 
International cooperation against match-fixing takes place from the legal aspect, as well as from the law enforcement aspect. The legal and legislative aspect calls for the adoption of state measures on the national as well as international level. The international legislative body, which started these measures of legislative activities on the international level, was the Council of Europe with its Convention on the Manipulation of Sports Competitions.

The Council of Europe, with the adoption of the Convention on the Manipulation of Sports Competitions, would like to be the supranational governmental organization in the fight against match-fixing. But the standpoint on definitions, from one point weak in terms of minimum standards and stubborn in terms of explanations regarding illegal sports betting, does not help. The problem of match-fixing is a global phenomenon, and the harmonization and coordination of the various measures with the help of all stakeholders are essential.

Cooperation, including the exchange of information and intelligence among national law enforcement authorities, is crucial for the success of investigations of cross-border crimes. To better fight against match-fixing and so investigate and prosecute criminals, it is crucial that the collection, analysis, and exchange of information and intelligence on match-fixing operates on the national and international level. The exchange of information should be safe and secure, otherwise, stakeholders will not share information. Safety and security of information is the most crucial step in collecting information; otherwise, members of a platform would not share information.

Match-fixing is a global cross-border crime that is exceedingly difficult to investigate as the many different countries employ a wide variety of methods, and some lack specific laws. Therefore, to apply a minimum standard by countries that want to tackle this phenomenon of match-fixing would be absolutely instrumental. These minimum standards could be applied and adopted by particular states; currently, the best option would be under the guidance of the Council of Europe within the cooperation of the Group of Copenhagen.

\section{Competing interests}

The author declares that there are no competing interests for any commercial associations or financial interests held by the author.

\section{Acknowledgments}

This paper was written with institutional support from Charles University, Prague, Czech Republic (SVV - Specifický vysokoškolský výzkum).

\section{Language proofreading}

Mravec is an ESL author. The text has been thoroughly revised by a native speaker.

\section{REFERENCES}

Boeri, T., Battista, S. (2013). Match Rigging in Italian Professional Soccer: The Economic Determinants of Corruption. In M.R. Haberfeld \& S. Dale, (eds.) Match-Fixing in International Sports. New York: Springer.

Bradley S. (2014). Swiss set to get tough over sports corruption. October 2014. Available at: https://www.swissinfo.ch/eng/ politics/new-rules_swiss-set-to-get-tough-over-sports-corruption/40801520. Accessed on 9 August 2021

Büchel, R. R. (2020). Time to act: Europe's political response to fighting the manipulation of sports competitions. Parliamentary Report Doc. 15116, Section C. 15 June 2020. Available at: https://pace.coe.int/en/files/28648/html. Accessed on 09 August 2021.

Carpenter, K. (2011). Match-Fixing - The Biggest Threat to Sport in the 21st Century? International Sports Law Review, 2, $13-24$. Council of Europe. (1992). European Sports Charter. Available at: https://rm.coe.int/16804c9dbb. Accessed on 9 August 2021. Council of Europe (2014). Explanatory Report to the Council of Europe Convention on the Manipulation of Sports Competitions. Available at: https://rm.coe.int/16800d383f. Accessed on 9 August 2021. 
Council of Europe (2020). Network of National Platforms (Group of Copenhagen). Available at: https://www.coe.int/en/ web/sport/network-of-national-platforms-group-of-copenhagen-. Accessed on 9 August 2021.

Council of Europe (2021). Chart of signatures and ratifications of Treaty 215. Available at: https://www.coe.int/en/web/ conventions/full-list/-/conventions/treaty/215/signatures?p_auth=5yuHb8tl. Accessed on 9 August 2021.

UEFA. (2013). European Football United for the Integrity of the Game 28 March 2013. Available at: https://www.uefa. com/MultimediaFiles/Download/uefaorg/Clubs/01/93/51/24/1935124_DOWNLOAD.pdf. Accessed on 9 August 2021.

European Commission. (2007). White Paper on Sport. Brussels, 11.July 2007. Available at: https://eur-lex.europa.eu/legalcontent/EN/TXT/PDF/?uri=CELEX:52007DC0391\&from=EN. Accessed on 9 August 2021.

European Union. (2012). Treaty on the Functioning of the European Union. Official Journal of the European Union C326/47. Available at: https://eur-lex.europa.eu/legal-content/EN/TXT/PDF/?uri=CELEX:12012E/TXT\&from=EN. Accessed on 9 August 2021.

EUROPOL. (2020). The involvement of organised crime groups in sports corruption. Situation report. Available at: https:// www.europol.europa.eu/sites/default/files/documents/the_involvement_of_organised_crime_groups_in_sports_corruption.pdf. Accessed on 9 August 2021.

Forrest, B. (2014). The big fix: the hunt for the match-fixers bringing down soccer. New York: William Morrow. ISBN 0062308076.

Gábriš, T. (2017). Effectiveness of European Countries' Laws and Regulations Dealing with Match-Fixing. Available at: https:// uefaacademy.com/wp-content/uploads/sites/2/2019/06/20170331_UEFAFinalReport_Gabris-Tomas.pdf. Accessed on 9 August 2021.

Godinho, L., Barbosa, C. (2013). Topics for an Academic Agenda:The Prevention of Match Fixing in Brazil. In M.R. Haberfeld \& S. Dale, (eds.) Match-Fixing in International Sports. New York: Springer.

Hill, D. (2008). The Fix: soccer and organized crime. Toronto: McClelland \& Stewart.

Honoré, T. (2002). The Necessary Connection between Law and Morality. Oxford Journal of Legal Studies, 22(3), 489-495. Available at: http://www.jstor.org/stable/3600656. Accessed on 21. October 2021.

Hutchins, B. (2014). Game, Set, Cash! - inside the secret world of international tennis trading. Carlton, Australia: Black Inc Books

ICSS (2014). Protecting the Integrity of Sport Competition - The Last Bet for Modern Sport. An executive summary of the Sorbonne ICSS Integrity Report, Sport Integrity Research Programme, 2012-2014, May 2014 Available at: http:// theicss.org/2019/03/12/icss-protecting-the-integrity-of-sport-competition-the-last-bet-for-modern-sport Accessed 9 August 2021.

IOC (2016). Handbook on Protecting Sport from Competition Manipulation. Interpol-IOC Integrity in Sport Initiative. Available at: https://stillmed.olympic.org/media/Document\%20Library/OlympicOrg/IOC/What-We-Do/Protecting-Clean-Athletes/ Betting/Education-Awareness-raising/Interpol-IOC-Handbook-on-Protecting-Sport-from-Competition-Manipulation. pdf. Accessed on 9 August 2021.

Kretchmar, R.S. From Test to Contest: An Analysis of Two Kinds of Counterpoint in Sport. Journal of the Philosophy of Sport, vol. 2, 1975, pp. 23-30.

Machová, M. (2015). Ovplyvňovanie výsledkov športových zápasov novým trestným činom? Časopis pro právní vědu a praxi. [Online]. 2015, č. 4. Available at: https://journals.muni.cz/cpvp/article/view/5282. Accessed on 9 August 2021.

Parry, J. (2020). The Concept of Sport in Olympism. Diagoras: International Academic Journal on Olympic Studies, 4, 2020, 131-148. Available at: http://diagorasjournal.com/index.php/diagoras/article/view/94. Accessed on 20. October 2021.

Perumal, W. R. (2014). Kelong Kings: Confessions of the world's most prolific match-fixer. Budapest: Invisible Dog

Tarasti, L. (2015). First International Convention Against Sport Manipulation. International Sports Law Review, 15, 2, $20-28$.

Trunz, M. (2016). Ein globaler Lösungsansatz zur Bekämpfung der Spiel- und Wettspielmanipulation im Sport. Zurich: Dike Verlag.

United Nations (2016). Resource Guide on Good Practices in the Investigation of Match-Fixing. Available at: https://www. unodc.org/documents/corruption/Publications/2016/V1602591-RESOURCE_GUIDE_ON_GOOD_PRACTICES_IN_THE_ INVESTIGATION_OF_MATCH-FIXING.pdf. Accessed on 9 August 2021.

Yogonet Gaming News. (2020) Maltese gaming industry sees nearly 10\% growth in 2019. Available at: https://www.yogonet. com/international/noticias/2020/06/24/53698-maltese-gaming-industry-sees-nearly-10por_ciento-growth-in-2019. Accessed on 9 August 2021. 